\title{
THE EFFECTIVENESS OF USAGE TRIACORTUM, CLOTRIMAZOLE AND DOXYCYCLINE FOR CHRONIC APICAL PERIODONTITIS TREATMENT
}

\author{
Korniichuk O. E., \\ Dnipro Medical Academy, assistant of the Department of Dentistry Faculty of Postgraduate \\ Education, PhD
}

DOI: https://doi.org/10.31435/rsglobal_ws/30062019/6571

\section{ARTICLE INFO}

Received: 25 April 2019

Accepted: 19 June 2019

Published: 30 June 2019

\section{KEYWORDS}

periadontitis, periapical tissues, microcirculation.

\begin{abstract}
This article represents the work for searching new and effective treatment modality for chronic forms of periodontitis with application of the antibiotic doxycycline, antifungal agent clotrimazole and glucocorticosteroid triacortum.

It was made the clinical judgement of treatment of 150 patients with chronic apical periodontitis. It was indicated an improvement of microcirculation in periodontitis tissue by Lazer Doppler flowmetry method by those patients who received therapy using proposed method of treatment and set of medication.
\end{abstract}

Citation: Korniichuk O. E. (2019) The Effectiveness of Usage Triacortum, Clotrimazole and Doxycycline for Chronic Apical Periodontitis Treatment. World Science. 6(46), Vol.3. doi: 10.31435/rsglobal_ws/30062019/6571

Copyright: (C) 2019 Korniichuk O. E. This is an open-access article distributed under the terms of the Creative Commons Attribution License (CC BY). The use, distribution or reproduction in other forums is permitted, provided the original author(s) or licensor are credited and that the original publication in this journal is cited, in accordance with accepted academic practice. No use, distribution or reproduction is permitted which does not comply with these terms.

Introduction. In the structure of the dental morbidity, chronic apical periodontitis occupies one of the leading places. Patients with various forms of apical periodontitis account for about $30 \%$ of the total number of patients seeking dental care [1]. In the course of numerous studies in the pulp in the initial stages of the development of the inflammatory process, many strains of facultative anaerobic streptococci and staphylococci were detected. It was found that among the causes of inflammation of the periapical tissues, the main role is assigned to microorganisms and their toxins, coming from the root canals to the periodontium. At the same time, anaerobic flora acts as an important pathogenic factor in apical periodontitis [3, 4].

Despite the large number of various physical factors and medications recommended in the treatment of patients with apical forms of periodontitis, it remains quite difficult to achieve the regeneration of the affected components of the periodontium. The rather low effectiveness of existing methods of treatment indicates the need to search for new methods of treatment of this pathology.

In this regard, the purpose of this study was to find a technique that increases the effects of antiseptic, antibacterial, fungicidal and immunotropic effects due to the combined use of drugs that ensure the effectiveness of treatment of patients with chronic apical periodontitis. By acting on the microflora of root macro and micro channels, we eliminate the influence of biogenic amines, reduce the level of the inflammatory process in the periodontal, create preconditions for the regeneration of periodontal tissues by increasing the effectiveness of treatment of chronic apical periodontitis using antibacterial rehabilitation of the root canal system. Using the results of clinical, microbiological research methods, as well as LDF data, we substantiated the expediency of using the proposed method of treating chronic forms of periodontitis in dental practice.

Materials and methods. We conducted a comprehensive clinical study of 150 patients with a diagnosis of chronic apical periodontitis, aged 18 to 52 years. Among the examined patients, 92 were women $(61.3 \%)$ and 58 men $(38.6 \%)$. 
Among the patients who came to the clinic with chronic granulating periodontitis were 68 people (45.3\%). Chronic granulating periodontitis was diagnosed in 19.3\% of persons aged 30-39 years, in $19.3 \%$ in the group $40-52$ years. A diagnosis of chronic periodontitis was made in 62 patients (41.3\%). The exacerbation of chronic periodontitis was in 20 patients (13.3\%).

All patients were divided into three groups depending on the method of treatment. Patients of all three groups received treatment for one month according to the same scheme: on the first visit in the root canals for a week they left the first temporary attachment, the nature of the investment corresponded to the observation group. During the second visit, patients of all observation groups in the root canals left calcium hydroxide (HYCAL) for a period of three weeks. This article reflects the immediate results obtained one week after the start of treatment.

In the main group of 50 people, the first week used doxycycline antibiotic therapy, clotrimazole antifungal drug to suppress microflora in the root canal, as well as a triacort, which includes triamcenolone acetonide, which has a pronounced antiallergic, anti-inflammatory and antiexudative effect.

Patients of the second group (the first comparison group - 50 people) received calcium hydroxide as a temporary attachment in the root canals during the first week after the start of treatment. In the third group (the second comparison group - 50 people), a paper pin impregnated with the drug cresophene was used as the first temporary attachmen.

Treatment efficacy and clinical changes were assessed using specific clinical evaluation criteria for patient complaints: no pain, a change in the nature of pain during percussion, as well as analysis of data obtained from microbiological studies and laser Doppler flowmetry data. Patients were selected in groups by the method of mechanical sampling in the order of admission to the clinic, taking into account the informed consent of the patient. For the evaluation of clinical symptoms, we developed evaluation criteria expressed in points $(0$ points is the norm; 1 point is a slight manifestation; 2 points is a pronounced manifestation; 3 points is an intense manifestation of the studied indicator). results

Research and discussion. The best clinical results by the end of the first week were achieved in the main group (therapy with the use of doxycycline, clotrimazole, triacort): $60 \%$ of patients reported improvement in pain and reduction in pain. The condition of the mucous membrane in the region of the causal tooth according to the evaluation criteria used in the work (hyperemia, edema, pain during palpation in the region of the transitional fold) improved in $24.4 \%$ of patients. A significant decrease in pain response during percussion was noted by $33.2 \%$ of people. Vasoparesis symptom was considered negative in $11.1 \%$ of patients. In the main group, the total indicator of complaints and manifestations of clinical symptoms significantly decreased compared with the baseline $(12.16 \pm 0.01)$ and amounted to $6.24 \pm 0.03$.

In the first comparison group, when using calcium hydroxide as a temporary investment by the end of the first week of therapy, $43.6 \%$ of patients noted an improvement in their condition. When examining patients of this group, objectively positive changes were noted in $18.6 \%$ of patients. When conducting a causal percussion, $83.7 \%$ of patients presented pain complaints with pressure on the tooth, while only $16.3 \%$ of patients showed a marked improvement. The condition of the mucous membrane around the causal tooth improved in $18.6 \%$ of patients according to the studied parameters. With percussion, $16.3 \%$ of people noted a significant improvement. Vasoparesis symptom was considered negative in $7.0 \%$ of patients. Positive changes were reflected in the overall clinical assessment relative to the baseline $(12.41 \pm 0.05)$ and amounted to $10.07 \pm 0.01$. However, in comparison with the total result of the main group, the results of the first comparison group are significantly worse $(\mathrm{p}<0.05)$.

In the second comparison group, in patients of which cresophene was used as a temporary attachment, a significant decrease in pain during nodding was noted by $7.9 \%$ of people, and hyperemia and mucosal edema decreased in $15.9 \%$ of patients. Vasoparesis symptom was considered negative in $5.3 \%$ of people. At the end of the week, the total indicator reflecting the clinical state of the patients of the second comparison group changed the least and amounted to $11.0 \pm 0.01$ versus $12.31 \pm 0.01$ before the treatment.

Patients of all observation groups conducted a study of the state of microcirculation in the projection of the apical part of the roots of the causal teeth (Table 1). 
Table 1.

\begin{tabular}{|c|c|c|c|c|c|c|c|}
\hline \multirow{2}{*}{$\begin{array}{c}\text { The } \\
\text { studied } \\
\text { indicator }\end{array}$} & $\begin{array}{c}\text { Conditional } \\
\text { physiological } \\
\text { norm }\end{array}$ & \multicolumn{2}{|c|}{ Primary } & \multicolumn{7}{|c|}{ First Comparison } & \multicolumn{2}{|c|}{ Second Comparison of observation } \\
\cline { 3 - 8 } & $\begin{array}{c}\text { Before } \\
\text { treatment }\end{array}$ & $\mathbf{1}$ week & $\begin{array}{c}\text { Before } \\
\text { treatment }\end{array}$ & $\mathbf{1}$ week & $\begin{array}{c}\text { Before } \\
\text { treatment }\end{array}$ & $\begin{array}{c}\text { Before } \\
\text { treatment }\end{array}$ \\
\hline $\mathrm{M}$ & $21,0-22,0$ & $\begin{array}{c}14,5 \pm 0,2 \\
* \mathrm{p}_{1}<0,05 \\
* * \mathrm{p}_{2}<0,05\end{array}$ & $\begin{array}{c}16,7 \pm 0,3 \\
\mathrm{p}_{1}<0,05 \mathrm{p}_{2} \\
<0,05\end{array}$ & $14,5 \pm 1,1$ & $15,2 \pm 0,9$ & $14,5 \pm 0,1$ & $14,9 \pm 0,2$ \\
\hline $\mathrm{Kv}$ & $12,0-15,0$ & $\begin{array}{c}11,1 \pm 0,2 \\
\mathrm{p}_{1}<0,05 \mathrm{p}_{2} \\
<0,05\end{array}$ & $\begin{array}{c}14,04 \pm 0,6 \\
\mathrm{p}_{1}<0,05 \mathrm{p}_{2} \\
<0,05\end{array}$ & $10,9 \pm 0,2$ & $11,1 \pm 0,3$ & $10,4 \pm 0,6$ & $10,7 \pm 0,6$ \\
\hline $\mathrm{a}$ & $2,20-3,30$ & $\begin{array}{c}1,67 \pm 0,1 \\
\mathrm{p}_{1}<0,05 \mathrm{p}_{2} \\
<0,05\end{array}$ & $\begin{array}{c}2,36 \pm 0,1 \\
\mathrm{p}_{1}<0,05 \mathrm{p}_{2} \\
<0,05\end{array}$ & $1,58 \pm 0,1$ & $1,7 \pm 0,1$ & $1,52 \pm 0,1$ & $1,6 \pm 0,1$ \\
\hline
\end{tabular}

Microvessels, being the most sensitive indicator, respond to pathogenic factors before the onset of clinical symptoms. The observation of the state of microcirculation in the tissues by the end of the first week of therapy in all groups revealed a change in the parameters of microcirculation. In the main group, the microcirculation index was $16.7 \pm 0.3 \mathrm{p}$. E., Which is significantly higher $(\mathrm{p}>0.05)$ before the treatment $14.5 \pm 0.2$ and indicates an improvement in the microcirculation. In the first comparison group, after a week, the microcirculation index was $15.2 \pm 0.9$ p. E., I.e., compared with pretreatment $(14, \pm 1.1)$, it did not increase significantly $(\mathrm{p}<0.05)$ and was significantly less $(\mathrm{p}<0.05)$ than in the main group. In the second group of comparison, the indicator of microcirculation was $14.9 \pm 0.2$ p. E., I.e., also increased insignificantly (p> 0.05). Thus, the state of periodontal microcirculation in the projection of the apex of the root of the causal tooth significantly improved by the end of the first week only in patients of the main group.

In the course of the work, a microbiological study of the contents of the root canals of patients obtained on the first visit before treatment and after antiseptic treatment of root canals with antiseptic solutions was performed (sodium hypochlorite solution 3\%, chlorhexidine solution 2\%). And also in the second visit after the evacuation of the first temporary investment in patients with chronic forms of apical periodontitis, members of all observation groups.

We used the method of culture (bacteriological) research of microorganisms, which includes several stages of working with the material obtained: material sampling using sterile H-file No. 15-25, sterile paper pins placed in $10 \mathrm{ml}$ of Schadler broth, transportation of material to the laboratory, sowing on solid nutrient media; incubation in a thermostat, identification of microorganisms in a mass spectrometer; Gram stain of the obtained cultures; determination of the sensitivity of microorganisms to the antibiotic doxycycline and the antifungal drug clotrimazole.

Representatives of aerobic, obligate-anaerobic, facultative-anaerobic types of respiration (table 2) were revealed by the method of cultivation in patients with chronic forms of periodontitis.

Table 2.

\begin{tabular}{|c|c|c|c|c|c|}
\hline Type of bacteria & $\begin{array}{c}\text { Before } \\
\text { treatment }\end{array}$ & $\begin{array}{c}\text { After antiseptic } \\
\text { processing }\end{array}$ & \multicolumn{3}{|c|}{$\begin{array}{c}\text { After evacuation of the first temporary } \\
\text { attachment }\end{array}$} \\
\cline { 4 - 6 } & & & \multicolumn{3}{|c|}{\begin{tabular}{c} 
Monitoring groups \\
\cline { 3 - 5 }
\end{tabular}} \\
\cline { 3 - 5 } & & & Primary & $\begin{array}{c}\text { The first } \\
\text { comparisons }\end{array}$ & $\begin{array}{c}\text { The second } \\
\text { comparisons }\end{array}$ \\
\hline Staphylicoccus aureus & 36,8 & 29,6 & 5,2 & 5,2 & 7,8 \\
\hline Actinomyces spp & 52,6 & 44,7 & 5,2 & 10,3 & 10,8 \\
\hline Escherichia coli & 68,4 & 52,3 & 2,6 & 7,8 & 21,0 \\
\hline Candida albicans & 50,0 & 40,2 & 0 & 7,8 & 15,7 \\
\hline Streptococcus & 73,7 & 58,0 & 10,5 & 13,1 & 15,7 \\
\hline Actinomyces israeli & 39,4 & 34,0 & 0 & 5,2 & 15,7 \\
\hline Enterococcus spp. & 31,5 & 26,3 & 0 & 2,6 & 7,8 \\
\hline Streptococcus spp. & 36,8 & 28,9 & 0 & 5,2 & 5,2 \\
\hline
\end{tabular}


Chronic destructive periodontitis is characterized by a significant development of the microbial landscape. Microbiological assessment of the persistence of virulent bacterial species in the root canal contents of all teeth with chronic periodontitis revealed a high contamination with microflora containing Staphylicoccus aureus, Actinomyces spp., Escherichia coli, Candida albicans, Streptococcus intermedius, Actinomyces Israeli, Enterococcus sop. After antiseptic root canal treatment, the proportion of patients in whom Staphylicoccus aureus was sown decreased from 36.8\% to $29.6 \%$, Actinomyces spp from $52.6 \%$ to $44.7 \%$, Escherichia coli from $68.4 \%$ to 52 , 3\%, Candida albicans - from 50\% to 40.2\%, Streptococcus intermedius - from $73.7 \%$ to $58.0 \%$, Actinomyces Israel - from $39.4 \%$ to $34.0 \%$, Enterococcus spp - from $31,5 \%$ to $28.3 \%$, Streptococcus spp - from $36.8 \%$ to $28.9 \%$.

A week later, the proportion of patients in whom the studied microorganisms were sown compared with the results obtained after antiseptic treatment decreased in all groups, but most significantly in the main observation group, in patients of which Candida albicans, Actinomyces Israeli, Streptococcus spp., Enterococcus spp . not sown at all.

The total number of sown microorganisms decreased relative to the results obtained after antiseptic treatment: Staphylicoccus aureus - by $11.4 \%$, Actinomyces spp - by $18.7 \%$, Escherichia coli - by $20.9 \%$, Candida albicans - by $15.5 \%$, Streptococcus intermedius - by $18.7 \%$, Actinomyces israeli - by $13.1 \%$, Enterococcus spp - by $15,9 \%$, Streptococcus spp - by $18,5 \%$.

Analysis of the immediate results obtained by us during the clinical, microbiological and LDF microcirculation studies proved the effectiveness of using the complex of doxycycline, clotrimazole, triacort as a temporary investment in root canals for treating chronic apical periodontitis in patients of the main observation group. By the end of the first week, the evaluation of the clinical picture in the main group was significantly better compared to the results obtained in the comparison groups. The results of the microbiological study showed that the number of strains seeded on average in one patient was 3.89 before treatment, after the first antiseptic treatment it was 2.97 , after evacuating the first temporary investment in the main group it was only 0.24 . In the comparison groups, the results were significantly worse: 0.58 in the first observation group and 1.00 in the second observation group $(\mathrm{p}<0.05)$.

The results of LDF microcirculation studies showed an improvement in tissue trophism by changing the state of microcirculation in the region of causative teeth in patients of the main group.

Our results generally show the effectiveness of the proposed therapy, justifying the use of the proposed drugs doxycycline, clotrimazole and triacort in the treatment of chronic forms of apical periodontitis.

\section{REFERENCES}

1. Mitronin A. B., Tsaryov V. N. Clinical and microbiological evaluation of the effectiveness of the end-canal application of the bioactive gel "collapse" in the treatment of chronic periodontitis // New in dentistry. - M., 2004. - № 5. - p. 50-60.

2. Borovsky E. V. Therapeutic dentistry / E. V. Borovsky (and others). - M .: Medicine, 2003. - 797 p.

3. Mashkovsky MD Drugs: A manual for doctors. - 15th ed., Revised., Rev. and add. - M .: RIA "New Wave", 2007. - 1206 p.

4. Antanyan A. A. // Endodontiya today. - 2007. - № 1. - p. 59-69.

5. Gutman J. L., Dumsha T. S., Lovedep P. E. Solution in endodontics: Prevention, diagnosis and treatment / Trans. from English - M., 2008. - 592 p.

6. Poltavsky Century. P. Intracanal medication: Modern methods. - M., 2007. - 88 p.

7. Epstein S. Antibiotics and the intraoral abscess / S. Epstein, I. W. Scopp // J. periodontol. - 1977. - № 48. - R. 236.

8. FabricusL. Oral bacteria and apical periodontitis: an experimental study in mokey // Thesis department of oral microbiology. University of Goteborg. - Goteborg, 1982. 